\title{
Electric hybrid airship with unlimited flight time
}

\author{
Yu. V. Pisarevskiy ${ }^{1}, V . B$. Fursov $^{2}, A . Y u$. Pisarevskiy ${ }^{1}, P . N$. Tatarnikov $^{3}, N . V$. Sitnikov $^{1, *}$, and S. A. Goremykin ${ }^{1}$ \\ ${ }^{1}$ Department of Electromechanical Systems and Power Supply, Voronezh State Technical University, Russia, 394026 Voronezh, \\ Moskovskiy pr. 14 \\ ${ }^{2}$ Department of Electric Drive, Automation and Control in Technical Systems, Voronezh State Technical University, Russia, 394026 \\ Voronezh, Moskovskiy pr. 14 \\ ${ }^{3}$ Department of Protective Structures, Federal State Government Issue Military Educational Institution of Higher Education "Military \\ Training and Scientific Center of the Air Force" Air Force Academy named after Professor N.E. Zhukovsky and Yu.A. Gagarin"
}

\begin{abstract}
This paper examines the possibility of using photoelectric energy conversion during creation of electric unmanned aerial vehicles of a hybrid type. These vehicles should operate at altitudes up to $22,000 \mathrm{~m}$ and have an unregulated flight time. The problems arising during creation of such devices are their instability and poor controllability. Also they possess a number of disadvantages typical for airships: large size and, as a consequence, high windage and dependence on weather conditions; low maneuverability and, as a consequence, the difficulty of landing. These negative aspects of all circular wings resulted in complete rejection of their development. However, the considered disadvantages show the feasibility of creating hybrid aircraft. Particular attention in this paper is given to disk-shaped vehicles. They have less windage, do not need to turn around when changing the direction of flight. The presence of solar panels in combination with modern control and navigation systems make it possible to create new unmanned aerial vehicles with unlimited flight time. The aircraft dimensions are calculated as a function of the lifted mass and other parameters. Recommendations on possible operation parameters of hybrid airship are given.
\end{abstract}

\section{Introduction}

Lighter-than-air aircrafts have been always caught attention [1-3]. Nowadays new materials, new power sources, more advanced solar panels, modern control and navigation systems are being created [4-9]. This contributes to the creation of new type of aircraft, in particular unmanned aerial vehicles with unlimited flight time [10-14]. The characteristic feature of airships is that they do not have a strictly defined limit on the mass of the transported cargo [15-18] in contrast to heavierthan-air aircrafts. The most significant advantages of airships are: higher reliability and safety in contrast to airplanes and helicopters; no strict limitations on carrying capacity; unlimited flight time; no need for runways.

However, it is necessary to itemize their disadvantages:

- Large dimensions and, as a consequence, high windage and dependence on weather conditions;

- Low maneuverability and, as a result, the difficulty of landing;

- Relatively low speed (up to $150 \mathrm{~km} / \mathrm{h}$ );

- High cost of filler gas - helium or the danger of hydrogen;

- Aerostatic imbalance, which forces one to carry a large amount of ballast onboard, which reduces the payload.
The considered disadvantages show the feasibility of creating a hybrid aircraft. Thus the aim of this work is to consider physical and engineering bases for creation of a new type of aircraft with unlimited flight time.

\section{Materials and methods}

Here we consider a new type of hybrid aircraft, which is formed by combining an airship with a helicopter. Such construction will have smaller dimensions than an airship and will enable elimination the problem of aerostatic imbalance. This increases the carrying capacity and efficiency of the vehicle. The maneuverability of vehicle is greatly increased, and the difficulties with landing of vehicle are eliminated. The use of an electric propulsion system together with a solar battery allows the development of unmanned aerial vehicles that do not require landing (atmospheric satellites). Currently operating atmospheric satellites are airplanes that operate at altitudes of 19,000 - 22,000 m and are rather fragile structures. Hybrid aircraft based on various types of aerostats compare favorably with airplanes, since they have a more reliable design and can lift more weight. These aircraft are compatible with solar panels, which require large areas to obtain sufficient electrical power. The shape of the considered aerostat is shown in Figure 1.

\footnotetext{
* Corresponding author: nvs17939@mail.ru
} 


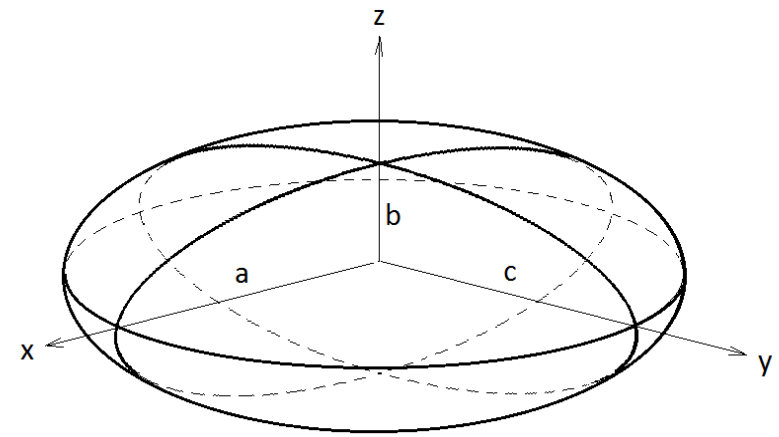

Fig. 1. Aerostat in the form of an ellipsoid of rotation.

It should be noted that the aerostat can be filled with a mixture of hydrogen and helium to provide greater lift, lower gas cost and, at the same time, operational safety. The presence of the aerostatic part changes the dynamics of the helicopter or multicopter flight, which requires the improvement of the control programs.

In the hovering mode, the thrust force of the propeller-driven groups $\left(F_{t}\right)$ must balance the weight of the aircraft together with the aerostatic lift (Archimedes force $F_{a}$ ). From this condition, it is possible to determine the required rotational speed of the propellers and the engines power required to provide the hovering mode of vehicle.

The power of engines, in turn, determines the required capacity of the storage battery and its weight (Arzamatsev and Kryuchkov 2014). For devices of this type, the hovering mode is the most power-consuming.

Obviously, these aircrafts have their own special area of application, that require a long flight time (more than 24 hours) or a high flight altitude (20,000-2,000 m), that can't be achieved by aircrafts of other types. The use of two different physical principles for maintaining an aircraft in the air significantly reduces the risk of its falling. The presence of an additional energy source significantly expands the aircraft capabilities. An additional source of energy can be used not only to power the power plant, but also to power the payload equipment. The lower boundary of the flight level is determined by the safety of device operation and must be outside the flight zone of civil aviation $(12,000 \mathrm{~m})$ and above the clouds. So, the solar battery can be used as the main source of electricity.

The following equation is used to determine the aircraft dimensions from the condition of equality between the aircraft weight and the aerostatic lift at a given height:

$$
\begin{gathered}
\frac{4}{3} \pi \cdot \beta_{1} \cdot\left(\rho_{\mathrm{air}}-\rho_{\mathrm{He}}\right) \cdot a^{3}- \\
-\left(2 \cdot \rho_{\text {shell }}+\rho_{\mathrm{sb}}\right) \cdot \pi \cdot k_{1} \cdot a^{2}-m_{\mathrm{r}}-M_{\Sigma}=0
\end{gathered}
$$

where

$$
m_{r}=2 \cdot \pi \cdot \mu_{r} \cdot n_{r} \cdot \sqrt{\frac{1+\beta_{1}^{2}}{2}} \cdot a,
$$

$$
k_{1}=1+\frac{\beta_{1}^{2}}{\sqrt{1-\beta_{1}^{2}}} \cdot \ln \frac{1+\sqrt{1-\beta_{1}^{2}}}{\beta_{1}}
$$

$\beta_{1}$ is the ratio between the semiaxes of the ellipsoid upon condition $a=c>b$

$$
\beta_{1}=\frac{b}{a}=0.25
$$

$\rho_{\text {air }}$ and $\rho_{\mathrm{He}}$ are densities of air and helium at the considered height, respectively $\left(\rho_{\text {air }}=0.08533 \mathrm{~kg} / \mathrm{m}^{3}\right.$, $\left.\rho_{\mathrm{He}}=0.0122 \mathrm{~kg} / \mathrm{m}^{3}\right)$;

$\rho_{\text {shell }}$ and $\rho_{\mathrm{sb}}$ are densities of the aerostat shell material and solar battery material, respectively $\left(\rho_{\text {shell }}=0.1 \mathrm{~kg} / \mathrm{m}^{2}, \rho_{\mathrm{sb}}=0.3 \mathrm{~kg} / \mathrm{m}^{2}\right)$;

$\mu_{\mathrm{r}}$ is the specific mass of carboxyl reinforcing elements, $\mathrm{kg} / \mathrm{m} ; \mathrm{n}_{\mathrm{r}}$ is the number of reinforcing elements $\left(\mu_{\mathrm{r}}=0.08 \mathrm{~kg} / \mathrm{m}, \mathrm{n}_{\mathrm{r}}=6\right)$;

$\mathrm{M}_{\Sigma}$ is the mass lifted by aerostat, which includes: mass of the traction electric motors $\left(\mathrm{m}_{\mathrm{mot}}\right)$, mass of the control system $\left(\mathrm{m}_{\mathrm{cs}}\right)$; mass of the accumulator battery $\left(\mathrm{m}_{\mathrm{ac}}\right)$, mass of the payload $\left(\mathrm{m}_{\mathrm{pl}}\right)$.

For flights at high altitudes from 12,000 to $22,000 \mathrm{~m}$, hybrid aircraft must be large, which predetermines a more complex aerostat design and shape. Further we consider a simplified design of an aircraft to determine the energy parameters of its power plant. As a basic condition, we assume that the aircraft should not descend below the level of $20 \mathrm{~km}$, i.e. the lifting aerostatic force must ensure that the vehicle hangs in the air in a deenergized state.

The excess pressure inside the aerostat shell is $\Delta \mathrm{P}=2$ $\mathrm{kg} / \mathrm{m}$, which is taken into account when determining the helium density. As a result, we obtain an equation equivalent to equation (1). The energy generated by solar batteries (SB) depends on its area $S_{\mathrm{sb}}$, efficiency $\eta_{\mathrm{sb}}$, time and season. If we assume that the surface area of solar battery covers half of the outer surface of the ellipsoid, then the average power generated by the solar battery is

$$
P_{s b}=1000 \cdot \eta_{s b} \cdot k_{u} \cdot k_{1} \cdot \pi \cdot a^{2}
$$

where $\eta_{\mathrm{sb}}$ is the efficiency of SB at $\mathrm{AM} 0,25^{\circ} \mathrm{C}$ in the optimal point of the current-voltage characteristics, $\mathrm{W} / \mathrm{m}^{2} ; \mathrm{k}_{\mathrm{u}}$ is the utilization factor of solar radiation, which depends on the coordinates of the aircraft in space, time, season.

Preliminary studies show that the presence of four stabilizing electric motors (Figure 2), with the appropriate adjustment of regulators, allows one to eliminate oscillations of the device, and it stabilizes. 


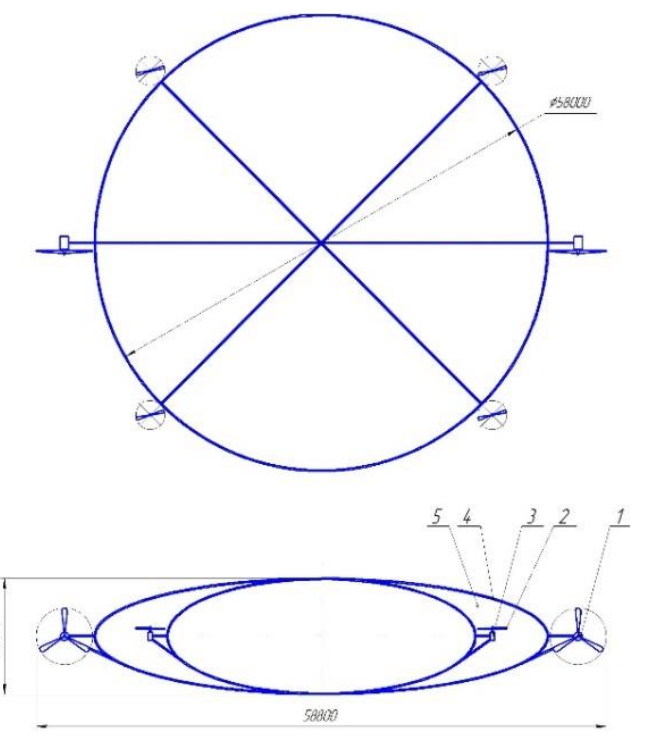

Fig. 2. Quadcopter-based hybrid aircraft (1 - traction motor; 2 vertical thrust screw; 3 - stabilizing electric motor; 4 - frame; 5 - shell).
The flight was stable even when the speed reached $100 \mathrm{~km} / \mathrm{h}$. Energy costs become very high already at such speeds. Vertical control can bring the drone to a predetermined height without changing buoyancy, using the wing effect. In this case, the lift is carried out by the oncoming air flow, which acts on the vehicle like on a wing. The device can maintain a given altitude only by moving, but this will require additional energy, as for the flight of an aircraft. Therefore, the solar battery must provide enough power for the aircraft to function.

\section{Results and discussion}

The aerostat dimensions were calculated as a function of mass $\mathrm{M}_{\Sigma}$, which the aerostat holds in the hovering mode at an altitude of $20,000 \mathrm{~m}$. The calculation results are summarized in Table 1.

According to Table 1, the dimensions of aerostat can be selected depending on the mass of the payload. For definiteness, consider an airship as a cellular repeater in the region of Ryazan, Russia. The cellular communication unit has the following parameters: power

Table 1. Relationship between dimensions of the aerostatic part of the airship and the mass $M \Sigma$, which is held by the aerostat in hovering mode at an altitude of $20,000 \mathrm{~m}$.

\begin{tabular}{|c|c|c|c|c|c|c|c|c|c|c|c|c|}
\hline \multirow{2}{*}{$\begin{array}{l}\text { Density of } \\
\text { shell material } \\
\rho_{\text {shell }}=0.1 \mathrm{~kg} / \mathrm{m}^{2}\end{array}$} & $\begin{array}{l}\text { Mass lifted by the } \\
\text { aerostat } \\
\mathrm{M}_{\Sigma}, \mathrm{kg}\end{array}$ & 0 & 40 & 80 & 120 & 160 & 200 & 240 & 280 & 300 & 320 & 340 \\
\hline & $\begin{array}{l}\text { Semimajor axis of } \\
\text { ellipsoid } a, m\end{array}$ & 24.4 & 25.2 & 25.9 & 26.6 & 27.2 & 27.7 & 28.2 & 28.7 & 28.9 & 29.2 & 29.4 \\
\hline Solar battery & $\begin{array}{l}\text { Average power of } \\
\text { the solar battery, } \\
\mathrm{kW}\end{array}$ & 297 & 317 & 335 & 351 & 367 & 382 & 396 & 410 & 417 & 424 & 430 \\
\hline
\end{tabular}

Note. Atmosphere parameters at a height of $20000 \mathrm{~m}$ : pressure $5468 \mathrm{~Pa}$; temperature $216.5^{\circ} \mathrm{K}$; air density $0.08533 \mathrm{~kg} / \mathrm{m}^{3}$.

SB characteristics: $\mathrm{psB}_{\mathrm{SB}}=200 \mathrm{~W} / \mathrm{m}^{2}$; specific mass $\rho_{\mathrm{SB}}=0.3 \mathrm{~kg} / \mathrm{m}^{2}$

Table 2. Energy indicators of cellular communication and airship control units.

\begin{tabular}{|c|c|c|}
\hline $\begin{array}{l}\text { Characteristic, its designation, meas. } \\
\text { unit }\end{array}$ & Calculation formula & Calculation results \\
\hline \multicolumn{3}{|c|}{ The cellular communication unit } \\
\hline Estimated battery capacity, C, A.h & $C=\frac{P_{c c} \cdot t}{U \cdot K_{p}} \cdot k_{z}$ & $C=\frac{300 \cdot 17}{24 \cdot 0.6} \cdot 1.2=425$ \\
\hline $\begin{array}{l}\text { Output rated current from the battery, I, } \\
\text { A }\end{array}$ & $I=\frac{P_{c c}}{U}$ & $I=\frac{300}{24}=12.5$ \\
\hline $\begin{array}{l}\text { The total amount of energy stored by } \\
\text { the battery, W, W.h }\end{array}$ & $W=U \cdot I \cdot t$ & $W=24 \cdot 12.5 \cdot 17=5100$ \\
\hline $\begin{array}{l}\text { Weight of batteries for the cellular unit, } \\
\mathrm{m}_{\mathrm{ac}}, \mathrm{kg}\end{array}$ & $m_{a c 1}=\frac{W}{\mu}$ & $m_{a c 1}=\frac{5100}{200}=25.5$ \\
\hline \multicolumn{3}{|c|}{ The airship control unit } \\
\hline Estimated battery capacity, C, A.h & $C=\frac{P_{s p} \cdot t}{U \cdot K_{p}} \cdot k_{z}$ & $C=\frac{320 \cdot 17}{24 \cdot 0.6} \cdot 1.2=453$ \\
\hline $\begin{array}{l}\text { Output rated current from the battery, I, } \\
\text { A }\end{array}$ & $I=\frac{P_{s p}}{U}$ & $I=\frac{320}{24}=13.3$ \\
\hline $\begin{array}{l}\text { The total amount of energy stored by } \\
\text { the battery, W, W.h }\end{array}$ & $W=U \cdot I \cdot t$ & $W=24 \cdot 13.3 \cdot 17=5440$ \\
\hline $\begin{array}{l}\text { Weight of batteries for the cellular unit, } \\
m_{a c 2}, \mathrm{~kg}\end{array}$ & $m_{a c 2}=\frac{W}{\mu}$ & $m_{a c 2}=\frac{5440}{200}=27.2$ \\
\hline $\begin{array}{l}\text { Weight of batteries for electric units, } \\
\mathrm{m}_{\Sigma}, \mathrm{kg}\end{array}$ & $m_{\Sigma}=m_{a c 1}+m_{a c 2}$ & $m_{\Sigma}=25.5+27.2=52.7$ \\
\hline
\end{tabular}


consumption $\mathrm{P}_{1}=300 \mathrm{~W}$; mass $\mathrm{m}_{\mathrm{el}}=47 \mathrm{~kg}$; dimensions $520 \times 400 \times 260 \mathrm{~mm}$. The airship control unit has the similar parameters: $\mathrm{P}_{1}=320 \mathrm{~W}$; mass $\mathrm{m}_{\mathrm{el}}=50 \mathrm{~kg}$; dimensions $530 \times 420 \times 270 \mathrm{~mm}$. The stabilization system includes four electric motors with a nominal power of $\mathrm{N}_{\mathrm{mst}}=1500 \mathrm{~W}$. Cellular communication equipment, airship control unit and stabilization system operate within 24 hours. During daylight hours, from 9 am to 3 pm, a solar battery works, which within 7 hours must ensure the batteries recharging and the vehicle operation at an altitude of $20,000 \mathrm{~m}$. The backup time for electrical equipment is $\mathrm{t}=17$ hours at a standard voltage $\mathrm{U}=24 \mathrm{~V}$. Assume that the permissible level battery discharge is $60 \%\left(\mathrm{~K}_{\mathrm{dc}}=0.6\right)$. The cellular communication unit and the airship control unit consume current of the same order, therefore, we consider these consumers separately. The obtained calculation results are summarized in Table 2 .

The total mass of the cellular communication and control units for the airship with batteries is

$$
\begin{aligned}
& M_{u c c}=m_{e l 1}+m_{e l 2}+m_{\Sigma} \\
& M_{u c c}=47+50+52.7=149 \mathrm{~kg} .
\end{aligned}
$$

The considered airship has a shape of an ellipsoid of rotation (Figure 2), and it predetermines the design of the power plant. It must have two traction electric motors with a direct drive of propellers, providing horizontal movement and four electric motors with propellers to ensure stable flight of the vehicle. The mass of these elements depends on the vehicle motion speed. For definiteness, we consider an airship with mass of $\mathrm{M}_{\Sigma}=320 \mathrm{~kg}$ (Table 1).

The resistance force of air is directed against the vehicle speed, its value is proportional to the typical area $S$, the medium density, and the squared speed $V$ :

$$
X_{0}=C_{x 0} \cdot \frac{\rho \cdot V^{2}}{2} \cdot S \text {, }
$$

where $C_{\mathrm{x} 0}$ is the dimensionless aerodynamic drag

\begin{tabular}{|c|c|c|}
\hline $\begin{array}{l}\text { Characteristic, its designation, meas. } \\
\text { unit }\end{array}$ & Calculation formula & Calculation results \\
\hline \multicolumn{3}{|c|}{ Traction electric motors } \\
\hline Typical area $S, \mathrm{~m}^{2}$. & $S=\pi \cdot a^{2} \cdot \beta$ & $S=3.14 \cdot 29^{2} \cdot 0.25=660.2$ \\
\hline $\begin{array}{l}\text { Power required to overcome the } \\
\text { ambient medium, } \mathrm{P}_{0}, \mathrm{~W}\end{array}$ & $P_{0}=C_{x 0} \cdot \frac{\rho_{c} \cdot V^{3}}{2} \cdot S$ & $P_{0}=0.1 \frac{0.085 \cdot 20^{3}}{2} \cdot 660.2=22533$ \\
\hline Power of traction motor $\mathrm{N}_{\mathrm{tm}}, \mathrm{W}$ & $N_{\mathrm{tm}}=\frac{P_{0}}{2 \cdot \eta_{v t}}$ & $N_{\mathrm{tm}}=\frac{22533}{2 \cdot 0.8}=14083$ \\
\hline The nearest standard power $\mathrm{N}_{\mathrm{st}}, \mathrm{W}$ & $N_{s t}$ & $N_{s t}=15000$ \\
\hline $\begin{array}{l}\text { Traction motor weight, } \\
\mathrm{m}_{\mathrm{tm}}, \mathrm{kg}\end{array}$ & $m_{\mathrm{tm}}=\frac{N_{c m}}{\mu_{\partial}}$ & $m_{\mathrm{tm}}=\frac{15000}{1000}=15 \mathrm{~kg}$ \\
\hline $\begin{array}{l}\text { Rated current consumed by the } \\
\text { electric motor } \mathrm{I}_{\mathrm{rc}}, \mathrm{A}\end{array}$ & $I_{r c}=\frac{N_{s t}}{\eta \cdot U}$ & $I_{r c}=\frac{15000}{0.8 \cdot 24}=781 \mathrm{~A}$ \\
\hline \multicolumn{3}{|c|}{ Stabilization system motors } \\
\hline $\begin{array}{l}\text { Power of stabilization system motor, } \\
\mathrm{N}_{\mathrm{ssm}}, \mathrm{W}\end{array}$ & $\mathrm{N}_{\mathrm{ssm}}$ & 1500 \\
\hline $\begin{array}{l}\text { Mass of stabilization system motor } \\
\mathrm{m}_{\text {ssm }}, \mathrm{kg}\end{array}$ & $m_{\mathrm{ssm}}=\frac{N_{\mathrm{ssm}}}{\mu_{\mathrm{ssm}}}$ & $m_{\mathrm{ssm}}=\frac{1500}{1000}=1.5$ \\
\hline $\begin{array}{l}\text { Rated current consumed by the } \\
\text { electric motor } \mathrm{I}_{\mathrm{rss}}, \mathrm{A} \text {. }\end{array}$ & $I_{\mathrm{rss}}=\frac{N_{\mathrm{ssm}}}{U \cdot \eta}$ & $I_{\mathrm{rss}}=\frac{1500}{24 \cdot 0.8}=78.1$ \\
\hline $\begin{array}{lcc}\text { Calculated } & \text { capacitance } & \text { of } \\
\text { accumulator battery, } \mathrm{C}_{\mathrm{cc}}, \mathrm{A} \cdot \mathrm{h} & \end{array}$ & $C_{c c}=\frac{n_{\operatorname{mot}} \cdot N_{s s m} \cdot k_{\mathrm{load}} \cdot t}{\eta P_{\max _{3}}}$ & $C_{c c}=\frac{4 \cdot 1500 \cdot 0.6 \cdot 17}{0.9 \cdot 24 \cdot 0.6} \cdot 1.2=4722$ \\
\hline $\begin{array}{l}\text { The total amount of energy stored by } \\
\text { the stabilization system batteries, } \\
\mathrm{W}_{\mathrm{cc}}, \mathrm{W} \cdot \mathrm{h}\end{array}$ & $W_{c c}=U \cdot\left(I \cdot k_{\text {load }}\right) \cdot t$ & $W_{c c}=24 \cdot(78.1 \cdot 0.6) \cdot 17=19119$ \\
\hline $\begin{array}{l}\text { Mass of batteries for stabilization } \\
\text { system, } \mathrm{m}_{\mathrm{cc}}, \mathrm{kg}\end{array}$ & $m_{c c}=\frac{W_{c c}}{\mu}$ & $m_{c c}=\frac{19119}{200}=95$ \\
\hline $\begin{array}{l}\text { Mass of batteries for main traction } \\
\text { system, } \mathrm{m}_{\mathrm{tr}}, \mathrm{kg}\end{array}$ & $\begin{array}{l}m_{t r}=m_{\Sigma}-m_{c c}-4 m_{s s m}- \\
-2 m_{t m}-M_{u c c}\end{array}$ & $\begin{array}{r}m_{t r}=320-95-4 \cdot 1.5- \\
-2 \cdot 15-149=40\end{array}$ \\
\hline $\begin{array}{l}\text { Total energy stored by a battery for } \\
\text { main traction system, } \mathrm{W}, \mathrm{W} \cdot \mathrm{h}\end{array}$ & $W=m_{t r} \cdot \mu$ & $W=40 \cdot 200=8000$ \\
\hline $\begin{array}{l}\text { Reservation time for traction system } \\
\text { operation, } t, \mathrm{~h}\end{array}$ & $t=\frac{W_{t r}}{U \cdot I}$ & $t=\frac{8000}{24 \cdot 781}=0.43(25 \mathrm{~min})$ \\
\hline
\end{tabular}
coefficient.

Table 3. Energy indicators of power plants providing motion and hovering of an airship. 
The power required to overcome this component of the drag force is proportional to the cubed speed

$$
P_{0}=C_{x 0} \cdot \frac{\rho \cdot V^{3}}{2} \cdot S,
$$

The power and weight of the power plant were calculated under the condition that it will provide the aircraft with motion at a speed of $V=20 \mathrm{~m} / \mathrm{s}(72 \mathrm{~km} / \mathrm{h})$. The calculation results are summarized in Table 3.

\section{Conclusion}

1. An electric hybrid airship can be created using the existing element base, but its flight time is limited by the recharge cycle of $\mathrm{Li}$-ion batteries and is approximately 5 years.

2. The safe operation of an aircraft is directly related to an accurate forecast of weather conditions in flight areas, which is typical for aviation in general and for airships in particular.

3. The electric power plant ensures the operation of the aircraft at altitudes up to $22,000 \mathrm{~m}$. The maneuvering range largely depends on the efficiency of the solar battery and the specific capacity of the storage batteries.

4. The considered aircraft does not make it possible to use the traction power plant within 24 hours, which can function normally only during daylight hours. Therefore, it is important to predict the atmospheric conditions for the nearest night time, which allows one to move the vehicle to a safe place during daylight hours within 6-7 hours.

\section{References}

1. S. Redi, G.S. Aglietti, A.R. Tatnall, T. Markvart, Dynamic response to turbulence of tethered lighterthan-air platforms., J. Aircr., 48, 540-552 (2011) doi:10.2514/1.C031137.

2. J.H.W. Hain, Lighter-than-air platforms (blimps and aerostats) for oceanographic and atmospheric research and monitoring. In Proceedings of the Oceans Conference Record (IEEE), 3, 1933-1936 (2000).

3. R. György, K. Broichhausen, J. Seifert, Potentials of lighter-than-air technology in future markets - An evaluation. In Proceedings of the ICAS Secretariat 26th Congress of International Council of the Aeronautical Sciences, ICAS 2008, 2, pp. 30243031 (2008).

4. GNSS-Global Navigation Satellite Systems: GPS, GLONASS, Galileo, and more. Choice Rev. Online 2008, doi:10.5860/choice.45-6185.

5. N. Ponomareva, A. Zvereva, E. Golubtsova, S. Ilyashenko, G. Ivanov, Certain economic instruments as a factor of realizing the potential of using alternative energy sources in Russia, E3S Web Conf., 124 (2019) doi:10.1051/e3sconf/201912405066.
6. D. Kraemer, B. Poudel, H.P. Feng, J.C. Caylor, B. Yu, X. Yan, Y. Ma, X. Wang, D. Wang, A. Muto et al., High-performance flat-panel solar thermoelectric generators with high thermal concentration, Nat. Mater (2011) doi:10.1038/nmat3013.

7. A.M. Mazur, , R. Domanski, Hybrid energy systems in unmanned aerial vehicles, Aircr. Eng. Aerosp. Technol (2019)

8. B.G. Dewanto, D. Novitasari, Y.C. Tan, D.D. Puruhito, Z.A. Fikriyadi, F. Aliyah, Application of Web 3D GIS to Display Urban Model and Solar Energy Analysis using the Unmanned Aerial Vehicle (UAV) Data (Case Study: National Cheng Kung University Buildings). In Proceedings of the IOP Conference Series: Earth and Environmental Science (2020)

9. K. Papis, R. Figaj, J. Kuś, M. Zołądek, M. Zając, Application of photovoltaic cells as a source of energy in unmanned aerial vehicle (UAV) - Case study, E3S Web Conf., 173, 02002 (2020) doi:10.1051/e3sconf/202017302002.

10. T. Villa, F. Gonzalez, B. Miljevic, Z.D. Ristovski, L. Morawska, An overview of small unmanned aerial vehicles for air quality measurements: Present applications and future prospectives, Sensors (Switzerland) (2016), doi:10.3390/s16071072.

11. K.P. Valavanis, G.J. Vachtsevanos, Handbook of unmanned aerial vehicles (2015) ISBN 9789048197071.

12. K. Anderson, K.J. Gaston, Lightweight unmanned aerial vehicles will revolutionize spatial ecology, Front. Ecol. Environ, 11, 138-146 (2013).

13. G. Rigatos, K. Busawon, Unmanned aerial vehicles. In Studies in Systems, Decision and Control, 152, 469-499 (2018).

14. I. Colomina, P. Molina, Unmanned aerial systems for photogrammetry and remote sensing: A review. ISPRS J. Photogramm. Remote Sens., 92, 79-97 (2014).

15. L. Liao, I.A. Pasternak, A review of airship structural research and development, Prog. Aerosp. Sci., 45, 83-96 (2009), doi:10.1016/j.paerosci.2009.03.001.

16. Airship Technology. Aircr. Eng. Aerosp. Technol. (1981).

17. Z. Zheng, W. Huo, Z. Wu, Autonomous airship path following control: Theory and experiments, Control Eng. Pract. (2013), doi:10.1016/j.conengprac.2013.02.002.

18. M.Z. Ashraf, M.A. Choudhry, Dynamic modeling of the airship with Matlab using geometrical aerodynamic parameters, Aerosp. Sci. Technol. (2013), doi:10.1016/j.ast.2011.08.014.

19. A.A. Arzamatsev, A.A. Kryuchkov, Mathematical models for engineering calculations of multi-rotor aircraft, Tomsk State Univ. J., 19, 1821-1828 (2014). 